\title{
Water Pollution Risk Assessment for Water Transfer Projects
}

\author{
Lan-lan SONG ${ }^{\text {a, }}$ and Jian-yun ZHANG $^{\text {b }}$ \\ Nanjing Hydraulic Research Institute, Nanjing 210029, China \\ E-mail: "amails1l@163.com, bjyzhang@nhri.cn
}

\begin{abstract}
Due to the imprecision of water environmental system and the repeated scarcity of quantitative information during transfer project, fuzzy theory might be an effective tool of the water pollution risk evaluation. Firstly, triangular fuzzy numbers of environmental parameters were defined. Then, fuzzy $\alpha$-cut technique is introduced to figure out the fuzzy expected values. Based on the concept of fuzzy reliability of "recipient" water quality, the water pollution risk in fuzzy terms is calculated. Finally, the implementation process of the water risk assessment method is explained by the case study.
\end{abstract}

Keywords- water transfer project, triangular fuzzy number, a-cut technique, water pollution risk, Taihu Basin

\section{INTRODUCTION}

Ever-increasing water demand of a booming economy, environmental degradation, and potential climate-related threats are challenges of water resource management in china. To solve uneven distribution of water resources in time and space, the Ministry of Water Resources proposed holistic integrated water resource management-oriented inter-basin water transfer projects and water system connectivity to match the growing demands on these precious natural resources[1]. In fact, Chinese water transfer project traced back to486 B.C, the Beijing-Hangzhou Grand Canal. To make up for the shortage water resources in north China, the South-to-North Water Diversion Project was brought up in the 1980s. Water transfer projects also have been effectively utilized to enhance water quality in many lakes, such as Lake Taihu, Xihu. However, the "donor" water quality takes effect on the "recipient" system. Yangtze River is the main "donor" river of these transfer projects. But, its $\mathrm{N}$ content doubled from 1980 to 1992[2]. These excess nutrients increase the production of "recipient" aquatic ecosystems, which often results in eutrophication. Inter-basin water transfers hydraulically connect two or more river basins that were hitherto unconnected. Diversions alter water allocation of river. Meanwhile, pollutants migration paths are changed with hydrological processes transmutation. River discharge is a key factor governing chemical components. Risk assessment is a sticking point for sustainable water management. It is necessary for prudence of the decisionmaker to calculate the percentage impact on "recipient" the water quality during diversion project.

A consequence of damage or loss of an event can be explained by risk. Most of the hazards cannot be controlled or predicted with an acceptable degree of accuracy [3]. Therefore, uncertainty plays an important role in water quality management problems [4]. One of uncertainty theories that has been arisen in these last decades is fuzzy theory [5], which can be utilized to incorporate epistemic uncertainty [6]. When quantitative information about environmental effects associated with the execution of activities and projects is restricted, imprecise and vague, fuzzy logic is a key solution to judge the optimal environmental harmony. Fuzzy logic has successfully involved in surface water quality management [7], groundwater contamination risk [8], water resource management [3] and environmental impact evaluation [9]. In addition, fuzzy sets and arithmetic can be found in several engineering applications [10]. With the development of fuzzy set theory, several new types of fuzzy numbers have been provided in succession in recent years. These new types include triangular or trapezoidal fuzzy numbers, Gaussian fuzzy number, lognormal-shaped fuzzy number, and Cauchy shaped fuzzy number. Numerous studies have developed triangular fuzzy numbers [11]. Since the concept of $\alpha$-cut technique was advanced, it has been widely applied in various subjects. $\alpha$-cut level reflects the different sets of numbers with a given minimum likeliness [12].

Therefore, fuzzy numbers of environmental parameters and suitable operators are put forward to estimate the "recipient" water pollution risk in transfer projects.

\section{BASIC PRINCIPLES OF RISK ANALYSIS OF TRIANGULAR FUZZY NUMBERS}

\section{A. Triangular Fuzzy Numbers}

Fuzzy numbers is a valid tool to compare consequence of the execution of activities and projects, especially to process incomplete data in environment impact and risk assessment.

The input space is mapped to a membership value $(\mu)$ by a membership function. If $X$ is the input space and its elements are denoted by $x$, then a fuzzy set $\tilde{A}$ in $X$ is defined as a set of ordered pairs.

$$
\tilde{A}=\left\{\left(x, \mu_{\tilde{A}}(x): x \in X\right)\right\}
$$

$\mu_{\tilde{\AA}}(x)$ is the membership function of $x \operatorname{in} \tilde{A}$. Each element of $X$ is transformed into membership value by the membership functions. The membership value varies between 0 and 1 .

Let us define a triplet $\left(a_{1}, a_{2}, a_{3}\right)$ as a triangular fuzzy number, where $a_{1} \leq a_{2} \leq a_{3}$. Suppose $\tilde{A}=\left(a_{1}, a_{2}, a_{3}\right)$, and its membership function is

$$
\mu_{\tilde{A}}(x)=\left\{\begin{array}{cc}
0 & \text { for } x<a_{1} \\
\frac{x-a_{1}}{a_{2}-a_{1}} & \text { for } a_{1} \leq x \leq a_{2} \\
\frac{a_{3}-x}{a_{3}-a_{2}} & \text { for } a_{2} \leq x \leq a_{3} \\
0 & \text { for } x>a_{3}
\end{array}\right.
$$




\section{B. A-Cut of A Triangular Fuzzy Number}

The $\alpha$-cut of fuzzy $\operatorname{set} \tilde{A}$ is a set consisting of those elements of the universe $X$ whose membership values exceed the threshold level $\alpha$. that is

$$
\tilde{A} \alpha=\left\{x \mid \mu_{\tilde{\AA}}(x) \geq \alpha\right\}
$$

A crisp interval is obtained by $\alpha$-cut operation. Then, $\alpha$ $\in[0,1]$ interval $A^{\alpha}$ is

$$
\begin{gathered}
A^{\alpha}=\left\{x \mid \mu_{A}(x) \geq \alpha\right\} \\
A^{\alpha}=\left[a_{L}{ }^{\alpha}, a_{R}^{\alpha}\right]=\left[\left(a_{2}-a_{1}\right) \alpha+a_{1},\left(a_{2}-a_{3}\right) \alpha+a_{3}\right]
\end{gathered}
$$

\section{WATER POLLUTION RISK ASSESSMENT METHOD FOR WATER TRANSFER PROJECTS}

\section{A. Definition of Triangular Fuzzy Numbers}

Let us consider that monitoring (or calculation) data of the environmental component may lie in between "recipient" environmental backgroundvalueand "donor" water environmental value during water transfer. Suppose that the most possible values of environmental component have normally been calculated by the complete river mixing mode.

The river mixing model is expressed as

$$
c_{m}=\left(Q_{s} c_{s}+Q_{b} c_{b}\right) /\left(Q_{s}+Q_{b}\right)
$$

Where, $c_{b}$ and $c_{s}$ denote the concentrations of a selected environmental component in the "recipient" and "donor" river, respectively; $Q_{b}$ is the flow in "recipient" river before transfer project; $Q_{s}$ is dilution flow in "donor" river.

Consequently, $c_{s}$ as the lower, $c_{b}$ as the upper and $c_{m}$ as the most possible values, we can define a triangular fuzzy parameterZ in water diversion, namely

$$
\tilde{Z}=\left(c_{\mathrm{s}}, c_{m}, c_{b}\right)
$$

We can approximately describe the membership function of fuzzy parameter $\tilde{Z}$ by Eq. (2). Then the general form of the $\alpha$-cut set of triangular fuzzy numbers is

$$
Z^{\alpha}=\left[\left(c_{m}-c_{s}\right) \alpha+c_{s},\left(c_{m}-c_{b}\right) \alpha+c_{b}\right]
$$

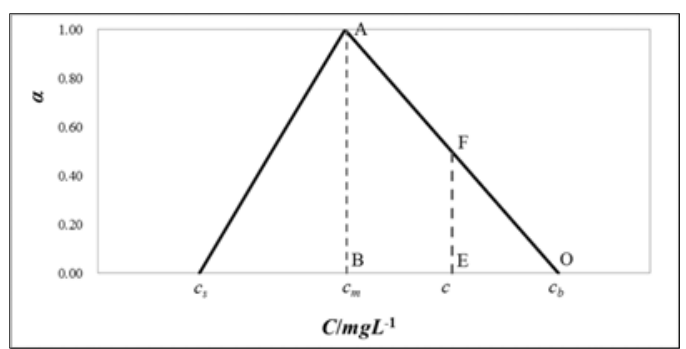

Figure 1. Triangular fuzzy curve of pollutant concentration.

\section{B. Determination of Water Pollution Risk}

Three possible types of "recipient" water quality exist during the transfer process. When $c_{j, i}>c_{b, j}$, the amount of degradation and dilution is less than that of any contaminants transported into the river from upstream; the pollution risk is 1 . When $c_{j, i}<\mathrm{cm}_{j, i}$, the "recipient" water quality is improved considerably for high biodegradable speed and increased dilution flow; The pollution risk is zero. When $c m_{j, i} \leq c_{j, i} \leq c_{b, j}$, the amount of degradation and dilution is greater than that of any contaminants transported into the river from upstream; Water transfer will improve the "recipient" water quality. But, there exists recontamination risk in the "recipient" water body. In order to assess the pollution risk of inter-basin transfer projects, a triangular risk coefficient $(R)$ was introduced.

A fuzzy measure of reliability or water pollution risk may be obtained as

$$
R=\left\{\begin{array}{cc}
0 & \text { for } c<c_{m} \\
S_{A B E F} / S_{A B O} & \text { for } c_{m} \leq c \leq c_{b} \\
1 & c>c_{b}
\end{array}\right.
$$

$S_{A B E F}$ is the area comprised between the representations of the membership function of $\tilde{Z}$ and $c$ and $S_{A B O}$ is the area under the representation of the membership function of $\tilde{Z}$.

The area between the membership function of $\tilde{Z \text { and }}$ its triangular approach in the descending section of the curve is

$$
S_{A B E F}=\int_{c_{m}}^{c} \mu_{\tilde{Z}}(c) d c
$$

The area under the triangular approach $\left(S_{\mathrm{ABO}}\right)$ is

$$
S_{A B O}=\int_{c_{m}}^{c_{b}} \mu_{\tilde{Z}}(c) d c
$$

\section{CASE STUDY}

The well-investigated Taipu River transfer project was utilized in this study as an example to assess water pollution risk.

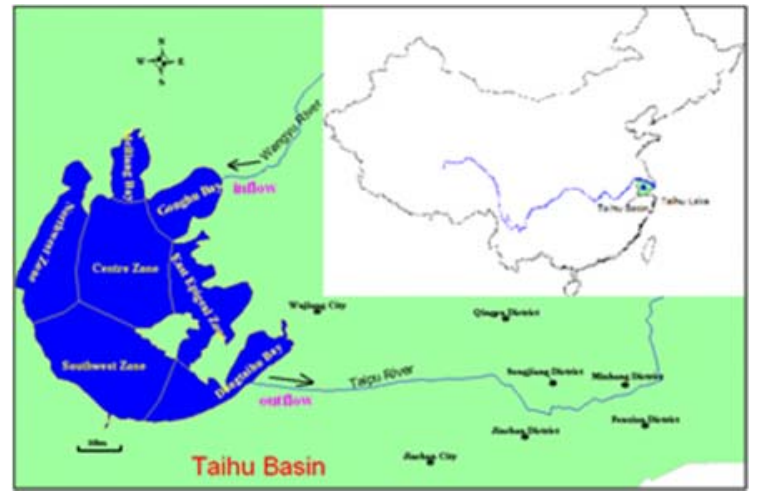

Figure 2. Seven subzones of Lake Taihu. The arrows in bold indicate the direction of the water transferred from Yangtze River to Lake Taihu. 
Located in the Yangtze River Delta Lake, Taihu basin, the most developed area in China, is approximately 36,900 $\mathrm{km}^{2}$ [13]. As a large shallow (mean depth of $1.9 \mathrm{~m}$ ) eutrophic lake, Lake Taihu is divided into seven subzones, Gonghu Bay, Meiliang Bay, Northwest Zone, Southwest Zone, Centre Zone, East Epigeal Zone, and Dongtaihu Bay, based on its hydrological characteristics, aquatic plant distribution, water quality condition, and topography (Fig.2). There are drinking water intakes around East Epigeal Zone and Dongtaihu Bay, as water quality good for aquatic macrophytes purification [14]. In order to improve water quality and suppress algal blooms, water transfer from the Yangtze River has been implemented since 2002 [13]. Preliminary experiment began on January 31 in 2002, ended on August 23 in 2007. Roughly 4512 million $\mathrm{m}^{3}$ water was transferred from the Yangtze River. Approximately 5 percent good-quality water entered Lake Taihu[15]. Wangyu River was served as inflow channel and Taipu River was served as outflow channel [14].

Taipu River is a channel that connects Lake Taihu and Huangpu River and has multiple functions of flood control, drainage of waterlogged areas, water supply, irrigation, shipping, and tourism. To date, six main water plants are dispersed along Taipu River and in the upstream of Huangpu River. From these rivers, approximately 5.98 million $\mathrm{m}^{3}$ of water are obtained every day as drinking water sources of surrounding cities, such as Shanghai, Wujiang, and Jiashan. However, water pollution and eutrophication in recent years have become chief limiting factors of sustainable development of the economy in Lake Taihu basin $[16,17]$. The water transfer to Huangpu River in 2006 began on March 17, ended on April 7. The inflow water quantity was controlled by Taipu sluice gate. When the water level of Dongtaihu Bay reached $3.14 \mathrm{~m}$, the sluice gate was opened to allow the water from Dongtaihu Bay to enter Taipu River until the level in the upstream sluice was equal to that in the downstream. The period from March 22 to March 29 is called the gate control period. Pump control period is from March 29 to April 4, where the sluice gate along Lake Taihu was closed and the pump stations of Taipu River were operated. Daily scheduling period is when the sluice gate was opened and the water level of Dongtaihu Bay exceeded $2.8 \mathrm{~m}$ but was less than $3.5 \mathrm{~m}$ (Table I ). By the end of the transfer, the total water from Dongtaihu Bay, 280 million $\mathrm{m}^{3}$, was added into Taipu River. $\mathrm{NH}_{4}{ }^{+}$concentration and water input rate were obtained from the seven sites (Fig.3).All sampling sites were monitored every day during the transfer experiment.

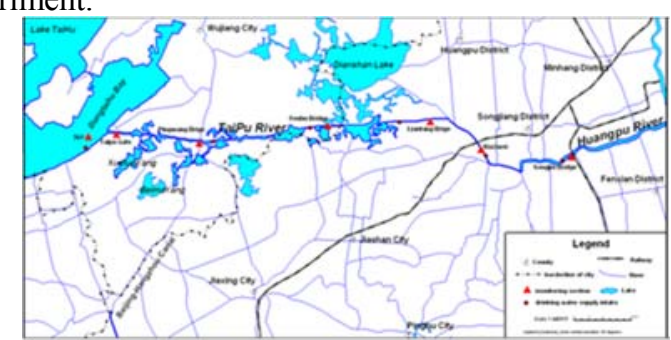

Figure 3. Map of the monitoring section of the water transfer experiment.
TABLE I. OPERATING STATE IN TRANSFER EXPERIMENT

\begin{tabular}{lllllll}
\hline $\begin{array}{c}\text { Time } \\
\text { interval }\end{array}$ & \multicolumn{1}{c}{ Time } & $\begin{array}{c}\text { TPflo } \\
\text { odgat } \\
\text { e }\end{array}$ & $\begin{array}{c}\text { TP } \\
\text { pump }\end{array}$ & $\begin{array}{c}\text { TP } \\
\text { River } \\
\text { inlet }\end{array}$ & $\begin{array}{c}\text { HP } \\
\text { River } \\
\text { inlet }\end{array}$ & $\begin{array}{c}\text { Control } \\
\text { flow }\left(\mathbf{m}^{3} / \mathbf{s}\right)\end{array}$ \\
\hline $\begin{array}{l}\text { Water } \\
\text { storage }\end{array}$ & $\begin{array}{l}2006 / 3 / 17- \\
2006 / 3 / 21\end{array}$ & $\mathrm{C}$ & $\mathrm{C}$ & $\mathrm{G}$ & $\mathrm{G}$ & $0-50$ \\
\hline $\begin{array}{l}\text { Gate } \\
\text { control }\end{array}$ & $\begin{array}{l}2006 / 3 / 22- \\
2006 / 3 / 29\end{array}$ & $\mathrm{C}$ & $\mathrm{C}$ & $\mathrm{G}$ & $\mathrm{G}$ & $50-300$ \\
\hline $\begin{array}{l}\text { Pump } \\
\text { control }\end{array}$ & $\begin{array}{l}2006 / 3 / 29- \\
2006 / 4 / 4\end{array}$ & $\mathrm{C}$ & $\mathrm{O}$ & $\mathrm{C}$ & $\mathrm{C}$ & $280-400$ \\
\hline $\begin{array}{l}\text { Daily } \\
\text { scheduling }\end{array}$ & $\begin{array}{l}2006 / 4 / 4- \\
2006 / 4 / 7\end{array}$ & $\mathrm{O}$ & $\mathrm{O}$ & $\mathrm{G}$ & $\mathrm{G}$ & $50-100$ \\
\hline TP: Taipu HP: HuangPuO:open & C:Close & G:good operation & & \\
\hline
\end{tabular}

Taihu lake water is contaminated by continuous discharge of industrial and domestic wastes for fast industrialization and urbanization. Meanwhile, raising fish culture in net-cage is major source of revenue of local residents of East Taihu (Dongtaihu Bay). Fish culture in this area has raised some environmental problems [18]. Riverine $\mathrm{NH}_{4}{ }^{+}$may come from industrial wastewater and domestic sewage along rivers [19]. The rapid ammonia nitrogen accumulation in the water is a result of farmed fish caused by fish excretion and the decomposition of unconsumed fish food. Ammonia nitrogen is toxic to all vertebrates, and the tolerable concentration levels of this compound for an aquacultural system are quite low, usually being much less than $1 \mathrm{mg} / \mathrm{L}$ [20].Water flow speed and the nitrification rate constant significantly increase during water transfer projects [21]. Ammonia nitrogen easy nitrifies under aerobic conditions. We also found that ammonia nitrogen is appropriate for the description of water quality changes during water transfer experiments. Therefore, we selected ammonia nitrogen to assess the degree of water pollution risk in the "recipient" water body.

\section{A. Definition of Triangular Fuzzy Numbers}

In this scenario, $\mathrm{NH}_{4}{ }^{+}$concentration of $36 \#$ was concentration of the "donor" area and reflected the quality of Dongtaihu Bay. The background concentration was the monitoring value of monitoring section (Table II ).

TABLE II. AMMONIA CONCENTRATION INTRANSFER EXPERIMENT (UNIT:MG/L)

\begin{tabular}{|c|c|c|c|c|c|c|c|}
\hline Date & 36\# & $\begin{array}{l}\text { Taipu } \\
\text { Gate }\end{array}$ & $\begin{array}{l}\text { Pingw } \\
\text { ang }\end{array}$ & $\begin{array}{c}\text { Fenh } \\
\text { u }\end{array}$ & $\begin{array}{l}\text { Lian } \\
\operatorname{tang}\end{array}$ & $\begin{array}{l}\text { Xiaz } \\
\text { iwei }\end{array}$ & $\begin{array}{c}\text { Song } \\
\text { pu }\end{array}$ \\
\hline $3 / 21$ & 0.18 & 0.63 & 0.79 & 1.17 & 0.63 & 1.71 & 2.10 \\
\hline $3 / 22$ & 0.22 & 0.35 & 0.50 & 1.40 & 0.84 & 1.71 & 2.05 \\
\hline $3 / 23$ & 0.11 & 0.23 & 0.32 & 2.07 & 0.93 & 2.47 & 2.29 \\
\hline $3 / 24$ & 0.26 & 0.34 & 0.48 & 1.20 & 1.04 & 2.51 & 2.60 \\
\hline $3 / 25$ & 0.24 & 0.51 & 0.40 & 1.23 & 0.95 & 2.34 & 2.29 \\
\hline $3 / 26$ & 0.25 & 0.27 & 0.31 & 0.96 & 0.79 & 1.91 & 2.50 \\
\hline $3 / 27$ & 0.32 & 0.33 & 0.60 & 0.79 & 0.57 & 0.70 & 2.30 \\
\hline $3 / 28$ & 0.28 & 0.38 & 0.46 & 0.69 & 0.47 & 1.30 & 2.13 \\
\hline $3 / 29$ & 0.21 & 0.36 & 0.44 & 0.60 & 0.39 & 1.26 & 1.99 \\
\hline $3 / 30$ & 0.22 & 0.31 & 0.39 & 0.62 & 0.45 & 1.00 & 1.73 \\
\hline $4 / 1$ & 0.3 & 0.33 & 0.60 & 0.60 & 0.33 & 0.75 & 1.42 \\
\hline $4 / 3$ & 0.18 & 0.38 & 0.54 & 0.51 & 0.21 & 0.82 & 1.21 \\
\hline $4 / 5$ & 0.11 & 0.22 & 0.38 & 0.39 & 0.22 & 1.10 & 1.41 \\
\hline $4 / 6$ & 0.1 & 0.23 & 0.38 & 0.51 & 0.21 & 1.32 & 1.36 \\
\hline $4 / 7$ & 0.1 & 0.21 & 0.74 & 0.91 & 0.29 & 1.39 & 1.53 \\
\hline $\begin{array}{l}\text { Quality level } \\
\text { experiment }\end{array}$ & pre- & III & III & IV & III & $\mathrm{V}$ & $>V$ \\
\hline
\end{tabular}


Take Taipu gate section as example. $\mathrm{NH}_{4}{ }^{+}$concentration of $36 \#$ and Taipu Gate were $0.18 \mathrm{mg} / \mathrm{L}$ and $0.63 \mathrm{mg} / \mathrm{L}$ on Mar. 21 before the transfer. The water inflow was $50 \mathrm{~m}^{3} / \mathrm{s}$, and the water discharge of Taipu Gate was $49 \mathrm{~m}^{3} / \mathrm{s}$ (Table III). The modal value of Taipu Gate was $0.40 \mathrm{mg} / \mathrm{L}$ by the river mixing model after the transfer. Then, the triangular fuzzy numbers of Taipu Gate section was $(0.18,0.40,0.63)$. By use of $\alpha$-cut technique, we can transform $C_{T 1}$ into the intervals of confidence at a certain $\alpha$-level. We can obtain

$$
C_{T 1}^{\alpha}=[0.18 \alpha+0.22,0.23 \alpha+0.63]
$$

TABLE III. WATER DISCHARGE IN TRANSFER EXPERIMENT (UNIT:M3/S)

\begin{tabular}{llllcccc}
\hline Date & $\begin{array}{c}\text { water } \\
\text { flow }\end{array}$ & $\begin{array}{c}\text { Taipu } \\
\text { Gate }\end{array}$ & $\begin{array}{c}\text { Pingw } \\
\text { ang }\end{array}$ & $\begin{array}{c}\text { Fen } \\
\text { hu }\end{array}$ & $\begin{array}{c}\text { Lianta } \\
\text { ng }\end{array}$ & $\begin{array}{c}\text { Xiazi } \\
\text { wei }\end{array}$ & $\begin{array}{c}\text { Song } \\
\text { pu }\end{array}$ \\
\hline $3 / 22$ & 50 & 49 & 116 & 128 & 225 & 173 & 288 \\
$3 / 23$ & 100 & 63 & 109 & 207 & 231 & 176 & 267 \\
$3 / 24$ & 100 & 104 & 172 & 288 & 348 & 272 & 451 \\
$3 / 25$ & 200 & 134 & 176 & 343 & 278 & 179 & 286 \\
$3 / 26$ & 200 & 222 & 247 & 155 & 197 & 111 & 198 \\
$3 / 27$ & 300 & 292 & 260 & 199 & 172 & 125 & 160 \\
$3 / 28$ & 300 & 308 & 299 & 160 & 117 & 84 & 98 \\
$3 / 29$ & 300 & 170 & 192 & 169 & 107 & 172 & 198 \\
$3 / 30$ & 280 & 282 & 246 & 189 & 157 & 117 & 99 \\
$4 / 1$ & 280 & 276 & 217 & 175 & 188 & 135 & 183 \\
$4 / 3$ & 280 & 277 & 193 & 182 & 234 & 176 & 230 \\
$4 / 5$ & 50 & 94 & 77 & 181 & 128 & 151 & 185 \\
$4 / 6$ & 50 & 49 & 112 & 149 & 143 & 263 & 455 \\
$4 / 7$ & 50 & 62 & 168 & 217 & 325 & 319 & 549 \\
\hline gate control & 168 & 196 & 206 & 209 & 318 & 450 \\
\hline pump control & 283 & 208 & 184 & 182 & 318 & 283 \\
\hline daily scheduling & 68.5 & 119 & 182 & 198 & 318 & 675 \\
\hline
\end{tabular}

B. Calculation of the Water Pollution Risk Based on Triangular Fuzzy Numbers under A-Cut

According to measured data of Taipu Gate on Mar.22, $\left(\mathrm{NH}_{4}{ }^{+}: 0.35 \mathrm{mg} / \mathrm{L}\right)$ was less than the modal value $(0.40 \mathrm{mg} / \mathrm{L})$. So, the water pollution risk $R_{T 1}$ is zero. In the same way, the triangular fuzzy numbers of the other monitoring section can be obtained, where $\tilde{C_{\mathrm{Pl}}}=(0.18,0.61,0.79), \tilde{\mathrm{C}_{\mathrm{Fl}}}=(0.18,0.89$, $1.17), \quad \tilde{C_{L 1}}=(0.18,0.55,0.63), \tilde{C_{X 1}}=(0.18,1.37,1.71)$ and $\tilde{\mathrm{C}_{\mathrm{S} 1}}=(0.18,1.82,2.10)$ on Mar. 22. Based on the water pollution risk $\mathrm{R}$ when considering five $\alpha$-cut for each fuzzy number, we can get the results that $R_{P 1}=0$, and $\mathrm{R}_{\mathrm{F} 1}=\mathrm{R}_{\mathrm{L} 1}=\mathrm{R}_{\mathrm{X} 1}=\mathrm{R}_{\mathrm{S} 1}=1.0$. The results presented in Table IV The pollution risk of water quality in the different periods was shown in Table V.
TABLE IV. POLLUTION RISK OF WATER QUALITY IN DIFFERENT PERIODS

\begin{tabular}{lllllll}
\hline Date & $\begin{array}{c}\text { Taipu } \\
\text { Gate }\end{array}$ & $\begin{array}{c}\text { Pingwan } \\
\mathbf{g}\end{array}$ & $\begin{array}{c}\text { Fenh } \\
\mathbf{u}\end{array}$ & $\begin{array}{c}\text { Liantan } \\
\mathbf{g}\end{array}$ & $\begin{array}{c}\text { Xiaziwe } \\
\mathbf{i}\end{array}$ & $\begin{array}{c}\text { Songp } \\
\mathbf{u}\end{array}$ \\
\hline $3 / 22$ & 0 & 0 & 1 & 1 & 1 & 1 \\
$3 / 23$ & 0 & 0 & 1 & 1 & 1 & 1 \\
$3 / 24$ & 1 & 1 & 0 & 1 & 1 & 1 \\
$3 / 25$ & 1 & 0.75 & 1 & 0.97 & 0.99 & 0.96 \\
$3 / 26$ & 0 & 0 & 0.87 & 0.90 & 0.93 & 1 \\
$3 / 27$ & 1 & 1 & 0.90 & 0.74 & 0 & 0.99 \\
$3 / 28$ & 1 & 0.50 & 0.93 & 0.78 & 1 & 0.99 \\
$3 / 29$ & 0.94 & 0.98 & 0.92 & 0.76 & 1.00 & 0.99 \\
$3 / 30$ & 0.78 & 0.91 & 1 & 1 & 0.91 & 0.97 \\
$4 / 1$ & 1 & 1 & 1.00 & 0.51 & 0.85 & 0.93 \\
$4 / 3$ & 1 & 0.93 & 0.85 & 0 & 1 & 0.94 \\
$4 / 5$ & 0 & 0 & 0 & 1 & 1 & 1 \\
$4 / 6$ & 1 & 1 & 1 & 0.97 & 1 & 0.99 \\
$4 / 7$ & 0.95 & 1 & 1 & 1 & 1 & 1 \\
\hline average & 0.69 & 0.65 & 0.82 & 0.83 & 0.91 & 0.98 \\
\hline
\end{tabular}

TABLE V. POLLUTION RISK OF WATER QUALITY IN DIFFERENT PERIODS

\begin{tabular}{llll}
\hline Site Name & $\begin{array}{c}\text { Gate control } \\
\text { period }\end{array}$ & $\begin{array}{c}\text { Pump control } \\
\text { period }\end{array}$ & $\begin{array}{c}\text { Daily scheduling } \\
\text { period }\end{array}$ \\
\hline Taipu Gate & 0.62 & 0.93 & 0.65 \\
Pingwang & 0.53 & 0.95 & 0.67 \\
Fenhu & 0.83 & 0.95 & 0.67 \\
Liantang & 0.89 & 0.50 & 0.99 \\
Xiaziwei & 0.87 & 0.92 & 1.00 \\
Songpu & 0.99 & 0.95 & 1.00 \\
\hline
\end{tabular}

V. CONCLUSION

Based on the fuzzy numbers, a new approach for fuzzy pollution risk analysis during transfer projects was put forward and proved to be very effective. From the transfer experiment, we found the "recipient" water quality improved remarkably when the transfer inflow was in range of 50$200 \mathrm{~m}^{3} / \mathrm{s}$. Notable abatement was in the concentration of ammonia nitrogen during the gate control period. When transfer inflow increase greater than $200 \mathrm{~m}^{3} / \mathrm{s}$ in pump control period, there is high pollution risk. The limited success of water transfer operation is a result of sediment re-suspension by scouring and more pollutants from upstream enters into water diversion channel. Therefore, the dilution inflow in a specific range reduces the degree of pollution risk. In the late daily scheduling period, high pollution risk means low dilution inflow can't maintain water good conditions. The water quality status returned to their original state. Contrast to the gate control period, dilution flow about $100-200 \mathrm{~m}^{3} / \mathrm{s}$ is appropriate. The highest pollution risk at Songpumeans water transfer experiment has little and no long-term effect on the water quality of upstream Huangpu River. Reducing the inputs of ammonia to the watershed would be a more feasible strategy to improve water quality than the transfer project, which seems to provide only a temporary improvement.

In this case, triangular fuzzy numbers can be converted into interval values that correspond to a specified confidence level of $\alpha$ through the use of $\alpha$-cut technique. This procedure not only decreases the fuzziness of the parameters but also 
enhances the practicability and flexibility of fuzzy arithmetic. The results of risk value estimations and the fuzzy expected values reflect the river pollution risk, which would provide the government and engineers with a more suitable and invaluable guide and overview on water quality and would clearly outline the policy and practice of conducting water transfer assessment. With fuzzy $\alpha$-cut technique, river pollution risk can be quantitatively evaluated and managed in a more effective manner. The total damage that arises from the transfer project can be minimized, and the effectiveness of water resource management can be enhanced. Lastly, if no measured data are collected, mathematical model of water quantity and quality is used for water pollution risk analysis.

\section{REFERENCES}

[1] Chen L, 2013. Water control plan of new stage. Oiushi Journal, 2, 5658(in Chinese)

[2] Su M.L, J. Zhang, H.T. Chen, et. al. ,2003. Nutrients in the Changjiang and its tributaries, Biogeochemistry,62,1-18

[3] El-Baroudy I, Simonovic S. P, 2004.Fuzzy criteria for the evaluation of water resource systems performance. Water Resources Research, $40,1-10$

[4] Rehana S, Mujumdar P.P, 2009. An imprecise fuzzy risk approach for water quality management of a river system. Journal of Environmental Management,90, 3653-3664

[5] Zadeh, L.A, 1965. Fuzzy Set. Information and Control. 8, 338-353

[6] Dutta P, Ali T, 2012. Uncertainty modeling in risk analysis: a fuzzy set approach. International Journal of computer applications,43,35-39

[7] Grifolla M, Campo D. A, Espino M, Mader J, et al.2013. Water renewal and risk assessment of water pollution in semi-enclosed domains: Application to Bilbao Harbour (Bay of Biscay). Journal of Marine Systems, 109-110 S241-S251

[8] Kumar N. V, Mathew S, Swaminatha G,2010. Multifactorial Fuzzy Approach for the Assessment of Groundwater Quality. J. Water Resource and Protection, 2, 597-608
[9] Peche R, Rodríguez E, 2011. Environmental impact assessment by means of a procedure based on fuzzy logic: A practical application. Environmental Impact Assessment Review,31,87-96

[10] Ross TJ.(1995) Fuzzy logic with engineering applications. McGrawHill, New York

[11] Zhou X. W, Wang L. P. ,Zheng B.H, 2008. "Ecological risk assessment of sediment pollution based on triangular fuzzy number", Huanjing Kexue, 29, 3206-3212(in Chinese)

[12] Kaufmann A, Gupta M.M (1985) Introduction to fuzzy arithmetic: theory and application. Van Nostrand Reinhold Co, New York

[13] Hu W, Zhai S, Zhu Z, Han H, 2008. Impacts of the Yangtze River water transfer on the restoration of Lake Taihu. Ecological Engineering,34, 30-49

[14] $\mathrm{Hu} \mathrm{L,} \mathrm{Hu} \mathrm{W,} \mathrm{Zhai} \mathrm{S,} \mathrm{Wu} \mathrm{H,2010.} \mathrm{Effects} \mathrm{on} \mathrm{water} \mathrm{quality} \mathrm{following}$ water transfer in Lake Taihu, China. Ecological Engineering, 36,471481

[15] Zhai S, Hu W, Zhu Z, 2010. Ecological impacts of water transfers on Lake Taihu from the Yangtze River, China. Ecological Engineering, 36,406-420

[16] Wang, H, Lu, J, Wang, W, Huang, P, Yin, C, 2007. Spatio-temporal distribution of nitrogen in the undulating littoral zone of Lake Taihu, China. Hydrobiologia 581,97-108

[17] Shen, J, Liu, E, Zhu, Y, Hu, S, Qu, W, 2007. Distribution and chemical fractionation of heavy metals in recent sediments from Lake Taihu, China. Hydrobiologia 581,141-150

[18] Qin Boqiang, XuPengzhu, Wu Qinglong, Luo Liancong, Zhang Yunlin.2007,Environmental issues of Lake Taihu, China. Hydrobiologia (2007) 581:3-14

[19] Duan S.W, Xu F, Wang L.J, 2007. Long-term changes in nutrient concentrations of the Changjiang River and principal tributaries. Biogeochemistry, $85,215-234$

[20] D.J Randall, T.K.N Tsui, 2002. Ammonia toxicity in fish. Marine Pollution Bulletin, $45,17-23$

[21] Cheng X, Zhang M.x, Sun C.j, 2001. Comparison of deoxygenation characteristics of suzhou creek before and after integrated low-flow augmentation project.Shanghai Environmental Sciences, 20,215217,230, in Chinese 